\title{
Comparativa cartográfica histórica para visualizar los cambios de identidad en el paisaje. Aplicación digital: La acequia Rascaña
}

\section{Historical cartographic comparative to show the changes of identity in the landscape. Digital application: The Rascaña canal}

\author{
TIPO DE TRABAJO: Comunicación \\ PALABRAS CLAVE \\ Cartografía histórica, cartografía interactiva, identidad gráfica.
}

KEY WORDS

Historical cartography, interactive cartography, graphic identity.

RESUMEN

Con la geografía moderna tuvo lugar el florecimiento de los mapas temáticos y, en consecuencia, la maduración de la cartografía cualitativa. Esta modalidad gráfica ofreció la posibilidad de plasmar los diferentes vínculos que el hombre establecía con un lugar determinado y al mismo tiempo, construía valores de identidad en el espacio. Con el actual auge en la visualización de datos, consideramos oportuno mostrar y rescatar datos que fueron claves en otro tiempo, en especial por el ejercicio de análisis del paisaje, a través de cartografías que corren el riesgo de desaparecer. De igual modo, señalamos la fuerte tendencia en los últimos tiempos hacia la defensa y el rescate de los paisajes culturales, como alternativa ante la uniformidad del espacio impuesto. Para ello, presentamos una aplicación artística interactiva llamada Identidad Nombres, resuelta con el software Unity $3 d$, a través del uso de componentes y botoneras para la configuración de la interacción, junto con una visualización en un espacio tridimensional, donde se muestran y contraponen dos cartografías históricas de distintos siglos, de un mismo lugar, el paisaje moldeado mediante la organización hidráulico de la huerta valenciana, y en concreto, un intervalo de la acequia de la Rascaña, una de las ocho acequias que estructuraban el entramado de la ciudad de Valencia y sus alrededores, cuyo recorrido consideramos especialmente relevante, por su contribución histórica y cultural.

\section{ABSTRACT}

Modern geography brought about a flowering of the thematic maps and, consequently, the maturation of the qualitative cartography. This graphic modality offered the possibility of capturing the different links that man established with a specific place. Built, at the same time, identity values in space. The current boom in the visualization of data, we consider it appropriate to show and rescue data that were key in another time, especially by the exercise of landscape analysis, through cartographies that run the risk of disappearing. This has involved, we point out the strong tendency in recent times towards the defense and rescue of cultural landscapes, as an alternative to the uniformity of the imposed space. For this, we present an interactive artistic application called Identity Names, solved with Unity $3 d$ software, through the use of components and buttons for the configuration of the interaction, together with a visualization in a three-dimensional space, where two historical cartographies are shown and contrasted in different centuries, of the same place, the landscape molded by the hydraulic organization of the Valencian garden, and in particular, an interval of the canal of the Rascaña, one of the eight ditches that structured the fabric of the city of Valencia and its surroundings, whose route we consider especially relevant, due to its historical and cultural contribution. 


\section{INTRODUCCIÓN}

En la actualidad, el reciclaje de las infraestructuras obsoletas tiene un doble sentido: el sentido funcional del re-uso y el sentido simbólico de revalorizar la memoria de la colectividad. Y para llevarlo adelante ha sido necesario crear una nueva cultura de la intervención en los paisajes existentes. (Maderuelo, 2007, p.202)

El mapa es un mecanismo inseparable del ser humano. La necesidad humana por trasladarse de un lugar a otro, de anotar, marcar el camino que conduce a otro enclave, en definitiva, nos ayuda a considerar la cartografía como una manifestación que convive desde sus orígenes con la humanidad. Pero en esta comunicación, mostraremos especial interés por una cualidad cartográfica, en concreto, por la capacidad de interpretar el espacio, incluso, nos atreveríamos a decir, por la de configurar espacio. Esta cualidad nos animó a la experimentación con el desarrollo de una aplicación cartográfica interactiva, que visualizaba la contraposición de elementos simbólicos descontextualizados de distintos mapas históricos, en relación a un mismo lugar.

Estas interpretaciones gráficas de la realidad se convierten en mediadoras entre el ser humano y el territorio que habita. De tal modo que, en estas representaciones, además del registro de localización espacial, aportan información de carácter social y cultural del momento, como ya manifestó en sus investigaciones Brian Harley sobre el signo cartográfico. Aportaciones que cuestionaron la mirada clásica sobre los mapas y contribuyó al inicio de la nueva perspectiva historiográfica sobre los mismos, como Parellada (2017) mencionaba “(...). Los significados de estos dependen del entrecruzamiento de contextos políticos e institucionales que los promueven" (p.316).

Ubicamos un gran momento de esplendor para la cartografía temática, con el surgimiento del concepto nación. Los artífices de la nueva sociedad, utilizaron los mapas por su eficaz contribución a ese orden y realidad. Facilitaban la configuración de una imagen de la nación y con ello, el desarrollo de un sentimiento patriótico, junto con un enfoque universal. "La tarea se reducía a sustituir las prácticas locales y dispersas por las administrativas del Estado, punto de referencia único y universal para toda medida y división del espacio" (Bauman, 2015, p.28). Así pues, el mapa era una herramienta de gestión y explotación sobre la humanidad y de planificación del espacio imaginado. Las nuevas ciudades crecieron en base a estos criterios espaciales, con diseños de espacios abiertos, por medio de enormes avenidas y plazas (Lefebvre, 1972). En consecuencia, no podemos catalogar estas herramientas como elementos autónomos y neutros, ya que deliberadamente quedaban retratadas algunas cosas y ocultas otras. Incluso llegamos a considerar que, a partir del ejercicio analítico sobre la gráfica de un mapa, se nos puede encaminar al entendimiento de la sociedad que favoreció su producción, en definitiva deberíamos tratarlos como "artefactos culturales" (Parellada, 2017, p.319).

\section{Urbanización y uniformidad}

El estudio de estos testimonios gráficos nos ha desvelado los cambios sociales y culturales de un territorio. En las líneas y trazados de un mapa encontramos el relato del proceso de evolución de una estructura social. Observamos múltiples funcionalidades y enfoques en el uso del mapa, como clasifica Conde (2015), "el mapa como sistema cognitivo, el mapa como cultura material, y el mapa como construcción social" (p.29). Por consiguiente, el mapa es protagonista en la manera de interpretar nuestra relación con el mundo. Desde esta óptica, encontramos el posicionamiento de Henri Lefebvre y el estudio de las relaciones sociales vinculadas en el espacio. La evolución de la sociedad, junto con las luchas de poder argumentaría los distintos paisajes que va adoptando. "Cada sociedad produce un espacio, su espacio" (Lefebvre, 2013, p.87). Podríamos considerar la ciudad y sus diferentes mutaciones, como el emplazamiento simbólico estratégico, en los últimos siglos. Como este código urbano, ha ido cambiando la relación, ciudad-campo. Por supuesto, el capitalismo ha sido el engranaje que ha impulsado los cambios en esta relación, en consecuencia, la ciudad medieval se transformó en la ciudad administrativa, vinculada al interés económico, de manera que la ciudad hoy es considerada una mercancía. Esta acepción del espacio, como valor de producción, o como un negocio (Harvey, 2008). Desencadenó en la ampliación de lo urbano y por este motivo, la urbanización del campo, el cual quedó sometido a las necesidades urbanas. En la actualidad, esta dinámica nos ha llevado a la negación y destrucción de la propia ciudad, paisaje complejo, polisémico, compuesto de valiosas capas simbólicas, ya que este modelo, a dado lugar a la uniformidad y anulación de este. La prioridad de la urbanización amenaza con la eliminación de los puntos de encuentro y convivencia, para transformarlos en mero tránsito (Lefebvre, 2013, p.21). El diseño de espacios pensados sólo para el consumo supone la reducción de las relaciones sociales y la anulación de otros modos de vida posible. A su vez, junto con la desaparición de cualquier otro tipo de infraestructura perteneciente al pasado y caída en desuso, pero dotada de una importante carga simbólica.

La urbanización, podemos concluir, ha desempeñado un papel crucial en la absorción de excedentes de capital, y lo ha hecho a una escala geográfica cada vez mayor, peor a costa de impetuosos procesos de destrucción creativa que implican la desposesión de las masas urbanas de cualquier derecho a la ciudad. (Harvey, 2013, p.39)

En resumen, los efectos de la globalización han desdibujado aquellas gráficas que ejemplificaban las relaciones establecidas con el entorno, las cuales iban quedando almacenadas como capas por el paso del tiempo, que permitían configurar un paisaje concreto. Ante este panorama, deberíamos de proponer como un derecho social, otras opciones de relación con nuestro territorio, buscando "los espacios de lo posible" (Lefebvre, 2013, p.24). En estos tiempos, existe una concienciación y actitud crítica ante esta degradación 
espacial. Nos encontramos con movimientos sociales en el ámbito urbano, redefiniendo otras vías de expresión, alejadas del simple consumo. En esta línea reivindicativa nos podemos servir nuevamente de la cartografía, por su mencionada cualidad de imaginar espacios, canalizada para construir narrativas alternativas. Asimismo, para visualizar y rescatar aquellos elementos simbólicos, que pueden correr el riesgo de desaparecer.

\section{METODOLOGÍA}

\section{Selección de los mapas}

Desarrollamos una aplicación artística interactiva llamada Identidad Nombres, con la intención de contraponer y analizar cartografías históricas de diferentes épocas. Así, a través de este mecanismo podríamos reflexionar sobre las distintas interpretaciones que adoptaba un paisaje tan relevante para el patrimonio histórico y cultural de la ciudad de Valencia y sus proximidades. En concreto, para esta experimentación nos centramos en un tramo del recorrido de la acequia Rascaña, una de las ocho acequias que componían el entramado hidráulico de la ciudad. Por consiguiente, seleccionamos dos tipos de planos bastante distintos en su solución gráfica. El primero se trataba de un plano de finales del siglo XVII, considerado como una de las tempranas cartografías históricas sobre los aledaños de la ciudad. Uno de los factores determinantes en su selección, fue el especial protagonismo que adoptaban los nombres propios en la representación: alquerías, molinos, núcleos urbanos, monumentos y algunos elementos singulares del lugar. Desde el punto de vista gráfico, destacaríamos la alta calidad de la caligrafía, como también las ilustraciones que figuraban en los distintos enclaves.

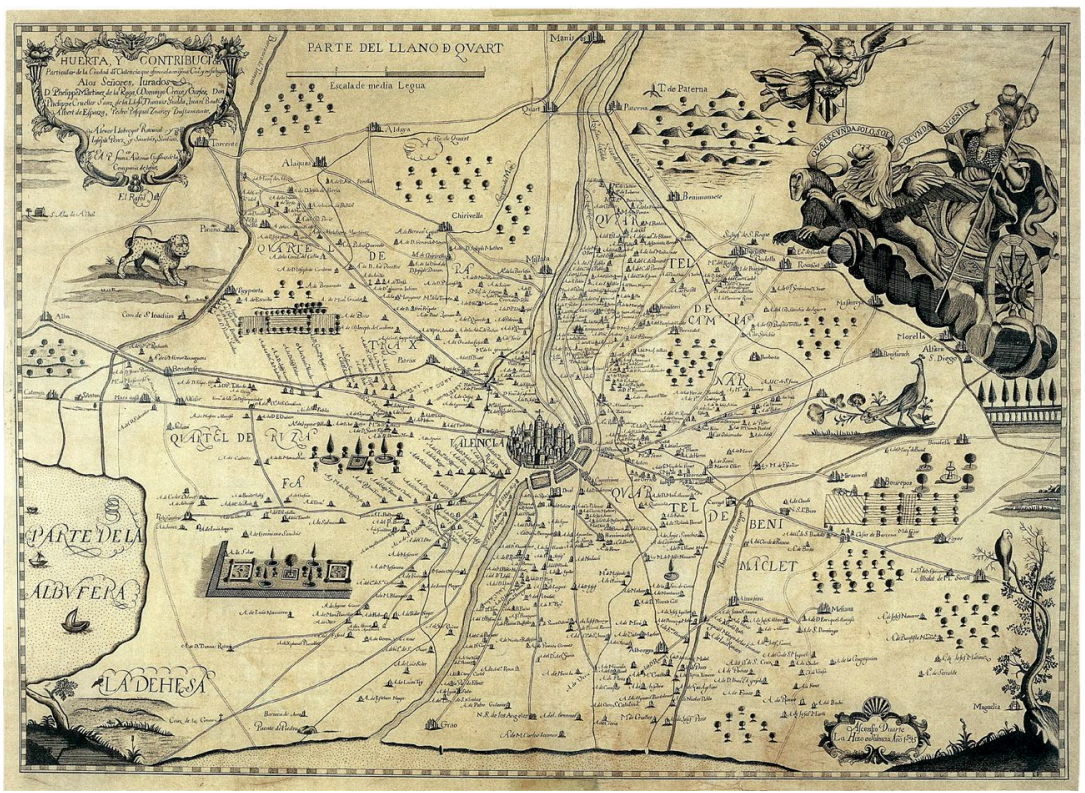

Figura 1. Plano denominado, Huerta y Contribución Particular de la ciudad de Valencia, 1695 de Francisco Antonio Cassaus.

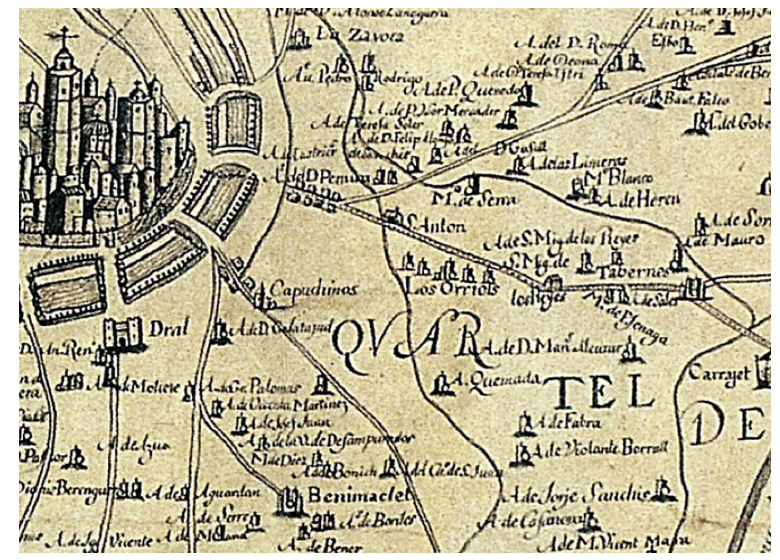

Figura 2. Detalle del plano Huerta y Contribución Particular de la ciudad de Valencia. 
En cuanto a la segunda opción, se basaba en los planos topográficos parcelarios rústicos y urbanos pertenecientes al municipio de Valencia. Estos planos son valorados, como una de las aportaciones técnicas más precisas y completas en datación de elementos, que se realizaron de la zona, durante el siglo XX. En consecuencia, esta actividad duró entre 1929 hasta 1944. A partir de estas dos representaciones, decidimos crear una nueva imagen cartográfica compuesta con la mezcla de las dos gráficas.

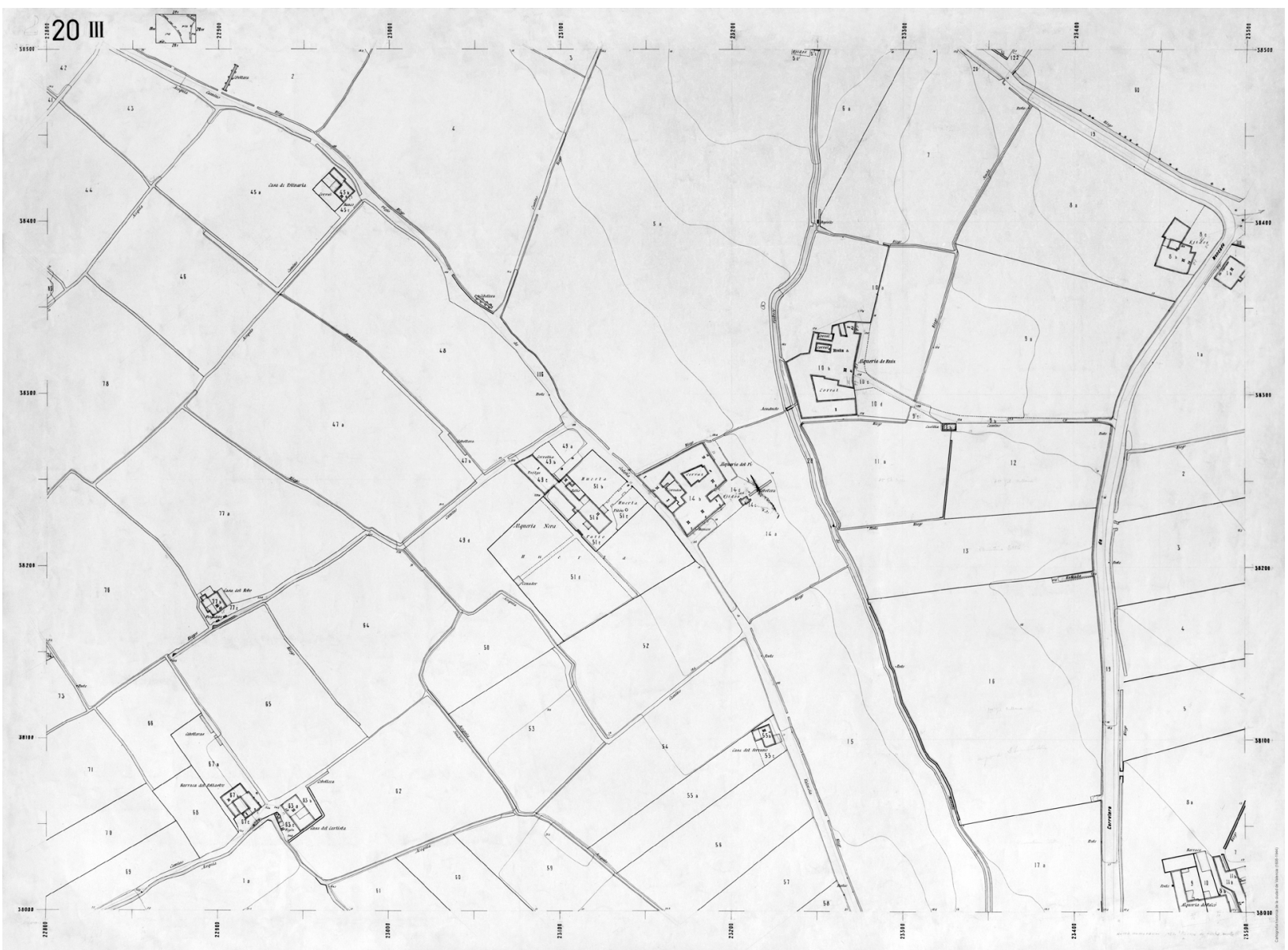

Figura 3. Plano del Término Municipal de Valencia, 1929-1944 del Instituto Geográfico y Catastral.

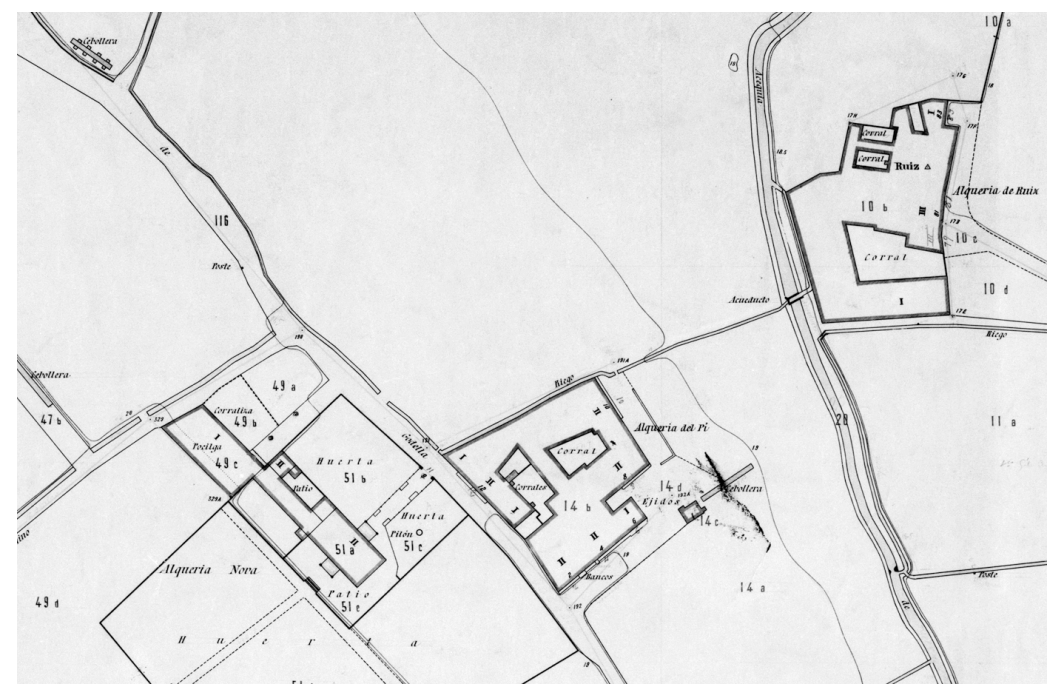

Figura 4. Detalle del Plano del Término Municipal de Valencia. 


\section{DESARROLLO}

\section{Tratamiento de los mapas}

Para la integración y combinación de los dos planos tuvimos que realizar tareas de edición de imagen. En referente, del primer mapa, el del siglo XVII, decidimos extraer los elementos caligráficos, por su alto grado simbólico y descartamos la visión espacial, por su tratamiento simplificado. Realizamos tareas de retoque en un software de imagen, con la finalidad de separar y aislar cada uno de los nombres propios de alquerías y molinos que recorrían nuestra acequia, en concreto, $\mathbf{6 2}$ nombres, acompañados de otros elementos que retrataban enclaves de interés de la zona seleccionada, como por ejemplo, la ciudad amurallada, monumentos, intervalos de vegetación y cultivo, etc... esta actividad nos llevó aproximadamente un mes.

Debemos mencionar en relación a la obtención de la imagen digitalizada del mapa del siglo XVII, que fue una ardua tarea. En primer lugar, el plano original no estaba accesible al público, ya que forma parte de una colección privada. Por otro lado, los facsímiles que localizamos no gozaban de buena calidad. Al final, la imagen definitiva la obtuvimos en la Cartoteca de la Universidad de Valencia.

\section{AredeRecaña}

Figura 5. Imagen editada del texto caligráfico del nombre de la acequia.

\section{TALENCICA}

Figura 6. Imagen editada del texto caligráfico del nombre de la ciudad.

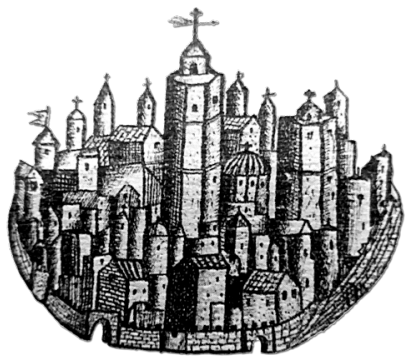

Figura 7. Imagen editada de la ilustración caligráfica de la ciudad amurallada.

Por otro lado, en el caso del Plano del Término Municipal de Valencia, su versión digitalizada fue obtenida de la publicación Cartografía histórica de la ciudad de Valencia (1608-1944).

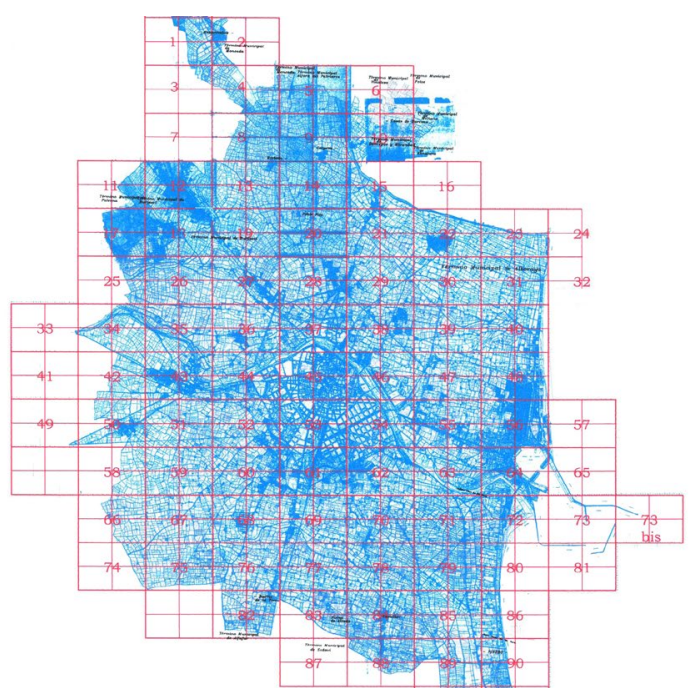

Figura 8. Fragmento de la composición de planos sobre el término de Valencia. 
Recopilamos del conjunto los planos correspondientes a nuestro tramo seleccionado de la acequia, en concreto, fueron: 14-IV, 15-III, 15-IV, 20-II, 20-IV, 21-II, 22-I, 22-II, 22-IV, 23-III, 28-II, 28-IV, 31-I, 31-II, 34-II, 35-I, 35-III, 35-IV, 36-III, 36-IV, 37-I, 37-II, 37-III, 43-II y el 44-I. Nuevamente, con un programa de edición de imagen, ordenamos y montamos los respectivos planos, con la finalidad de componer en una sola imagen todo el trayecto.

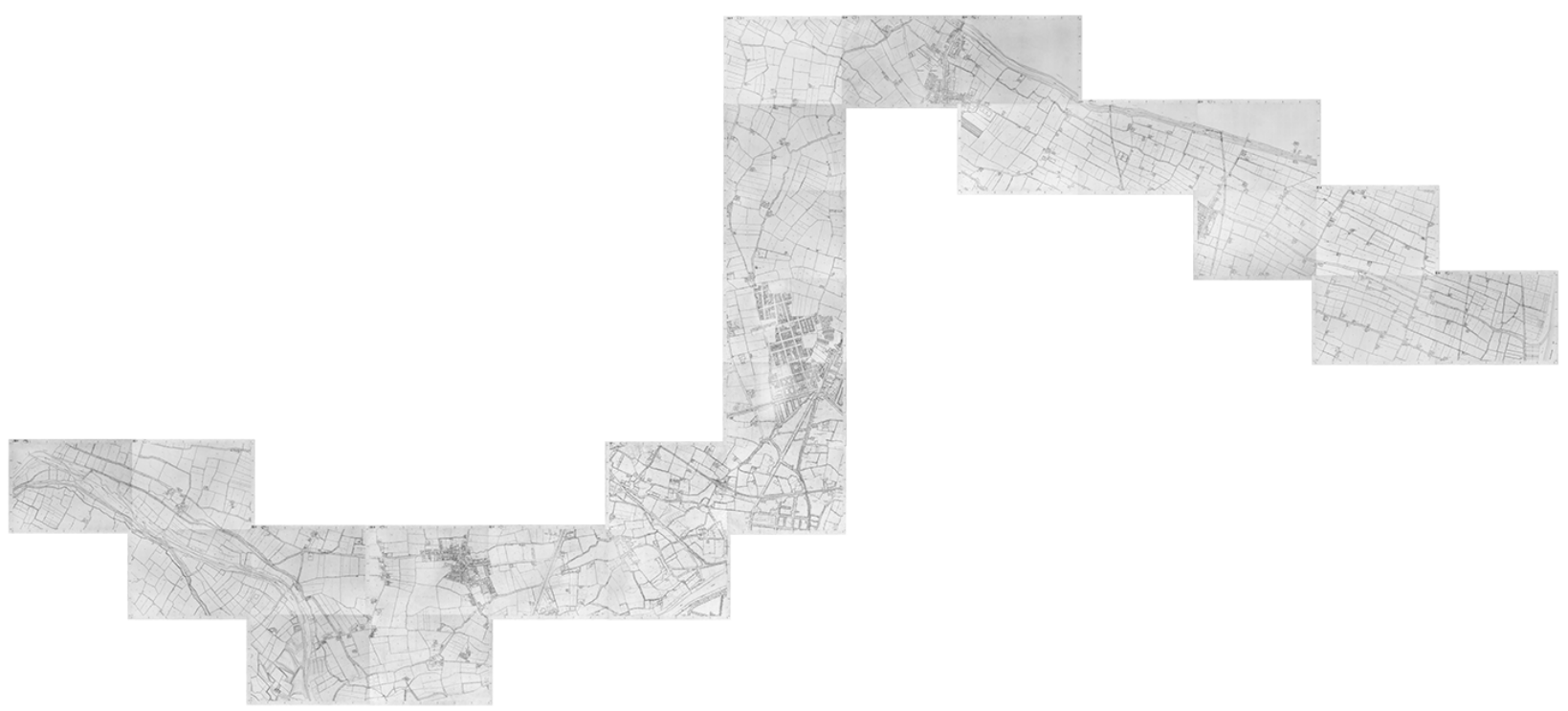

Figura 9. Imagen compuesta con los planos del recorrido.

\section{Aplicación en Unity}

Con el material gráfico definitivo pasamos a la siguiente etapa, que consistía en el desarrollo de una aplicación interactiva con el software Unity 3D. La aplicación se diseñó con una interfaz en dos dimensiones y con una resolución de pantalla de 1920 x 1080 px. Mediante esta interfaz se planteó una narración en dos escenas distintas. En la 10 escena, determinamos mostrar todos los nombres de las alquerías y los molinos del plano del siglo XVII. Pero, con un tipo de lectura estática, es decir, expuestos ordenadamente en las dimensiones de la interfaz y sin ningún tipo de interacción. El propósito era facilitar al usuario una visualización detenida y contemplativa de todos los nombres. Volvemos a reseñar tanto la calidad caligráfica, como la variedad y riqueza en cada registro, pues cada nombre aparecía con un tratamiento personalizado en la elaboración del texto, y además acompañado con la iconografía correspondiente.

\section{CAzedeRecaña 1}
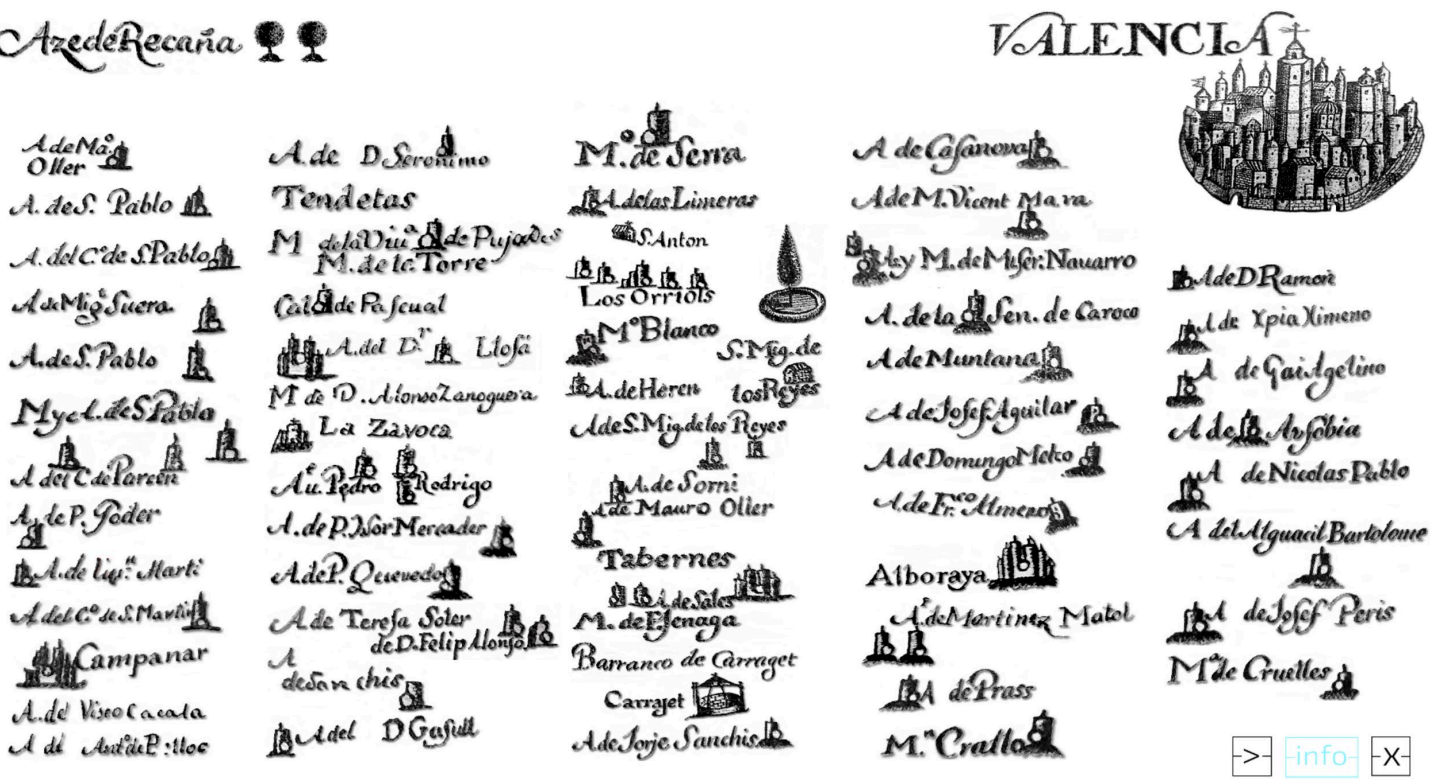

Figura 10. Imagen de la 1o escena de la aplicación interactiva. 
En relación a la 2a escena, establecimos la mezcla de representaciones gráficas. Por un lado, planteamos un espacio tridimensional a partir de la disposición en profundidad (eje Z) de la imagen compuesta del Plano del Término Municipal de Valencia, del siglo XX. A continuación, ubicamos en ese espacio tridimensional creado, cada uno de los nombres propios, del plano de Cassaus del siglo XVII. En esta tarea, detectamos bastantes correspondencias de elementos, entre las dos representaciones. Pero, de manera simultánea, durante el cotejo de los nombres en ambos planos, nos quedamos bastante sorprendidos ante la desaparición de muchos de ellos, en contraposición con el plano del siglo XX, en definitiva, la riqueza de nombres de alquerías y molinos que componían el paisaje retratado por Francisco Antonio Cassaus había sido drásticamente reducido en un par de siglos.

La interacción quedó delimitada con una botonera de tipo slider que habilitaba la visualización del recorrido de la acequia, en el espacio tridimensional. Este recorrido, decidimos resolverlo a través de un componente de animación, en concreto, utilizamos la cámara del entorno 3D, para realizar una grabación de desplazamiento por el trayecto de la acequia. Después programamos un script, con el cual poder sincronizar la reproducción de la animación de la cámara, con el deslizamiento del manejador de la botonera mencionada.

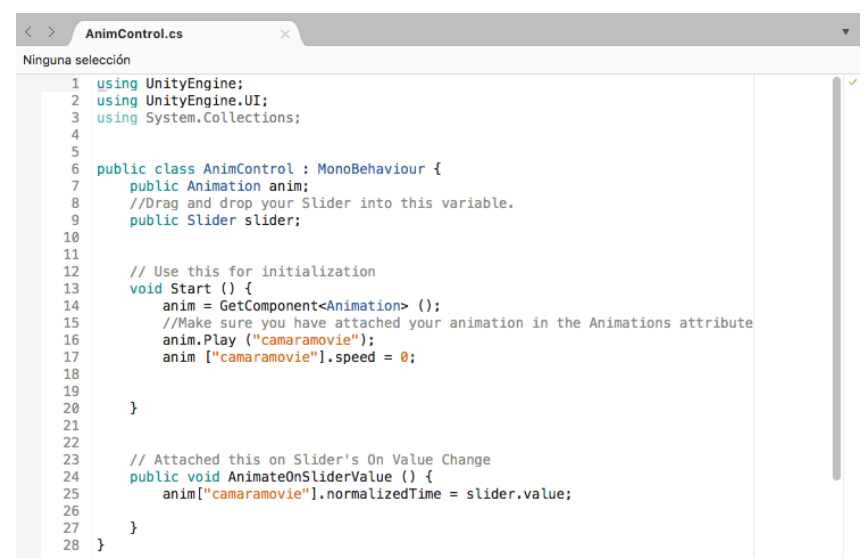

Figura 11. Imagen del script creado para la interacción de la botonera slider.

En última instancia, consideramos para una apropiada lectura de la aplicación interactiva, que debíamos añadir una escena de carácter introductorio, con una breve descripción del contenido y acompañada con unas instrucciones de usabilidad sobre la interacción. Por tanto, añadimos otra botonera en la parte inferior derecha de la interfaz, que habilitara la navegación entre escenas. Esta botonera quedó compuesta, con los siguientes botones:

Un primer botón con una apariencia en forma de texto, con la palabra "INFO", cuya interacción facilitaba el acceso a la primera escena, y así, el usuario tenía acceso a la información de la aplicación en todo momento. Un segundo botón con una apariencia en forma de flecha, cuya interacción permitía la navegación entre la segunda y tercera escena. Por último, un tercer botón con una apariencia en forma de aspa, que facilitaba la salida de la aplicación.

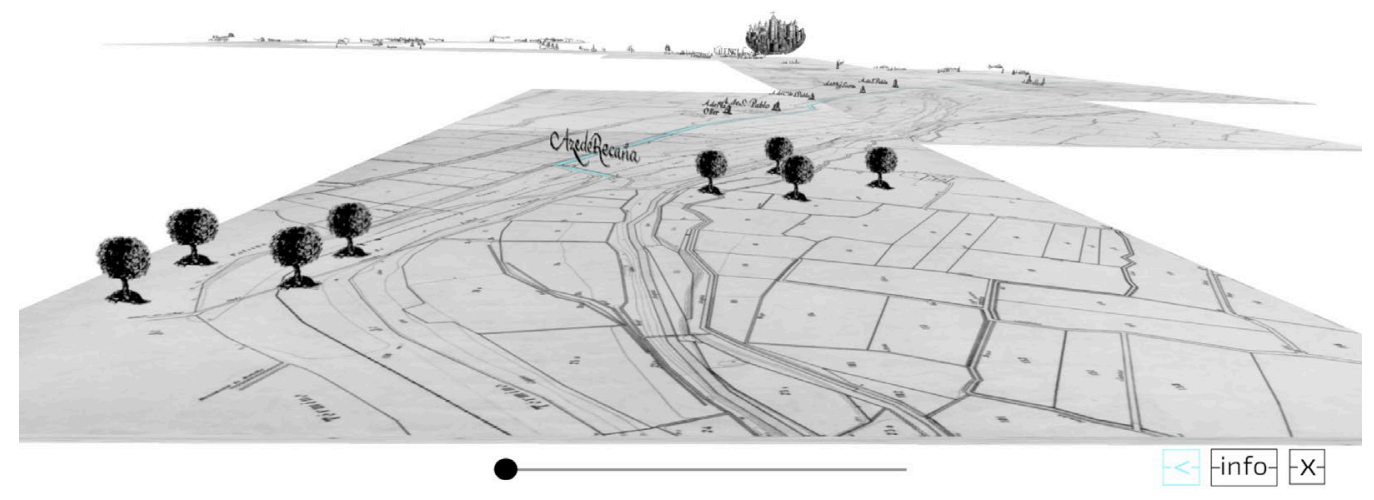

Figura 12. Imagen de la 2o escena de la aplicación interactiva. 


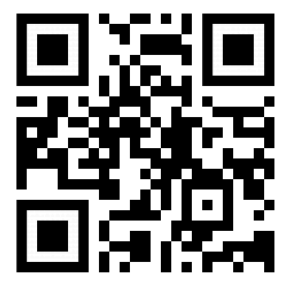

Figura 13. Código QR que enlaza con un vídeo de simulación de la aplicación interactiva.

https://vimeo.com/274318291

https://www.cartografiarascanya.com/

\section{CONCLUSIONES}

Con la aplicación artística interactiva hemos buscado la experimentación, por medio de la mezcla de cartografías y lenguajes gráficos de distinta naturaleza. Para poder descubrir conexiones, coincidencias, o pérdidas en el paisaje definido por la acequia de la Rascaña. Igualmente, con esta comparativa pretendíamos crear otras alternativas de producción de espacio, donde era crucial la contemplación de elementos simbólicos del pasado. "la cartografía no solamente consiste en hacer mapas, sino en construir mundos" Harley, (Lladó, 2012, p.170). Apostamos por un modelo de producción de espacio, que conozca, entienda y proteja los paisajes culturales.

Para Maderuelo (2007), el paisaje constituye el reflejo de una mirada cultural, de quien contempla. Un paisaje cultural debería contener connotaciones estéticas y una sensibilidad contemplativa (Corbera). En la etapa posmoderna, detectamos que dicho término ha sufrido una simplificación y pérdida de valores. Ante esta situación degenerada del paisaje, le debemos añadir los actuales factores climatológicos, de contaminación, junto con todos los problemas ecológicos existentes. De ahí que, necesitemos un cambio de actitud, donde las futuras intervenciones arquitectónicas aprendan a convivir, con esas capas del pasado. Interactuar con el entorno, pero estableciendo un diálogo. Respetar lo existente, reciclar aquellos elementos en desuso, y en todo momento, no perder el significado ni la identidad de un territorio, porque a fin de cuentas acabaremos desorientados. Igualmente, con este cambio podremos alejarnos finalmente del erróneo posicionamiento moderno, donde triunfa lo efímero y fracasa la memoria. Como dice Maderuelo (2007) "el impulso proteico de solo saber construir destruyendo" (p.201). Desde esta perspectiva, podemos exponer que el grado de intensidad de la urbanización nos encamina hacia la desubicación. Creando espacios urbanos clonados, “(...) como fotocopias confundiendo al viajero/habitante en su esfuerzo por captar el sentir del lugar" (Paz, 2011, p.406). Este modelo social ha sido fruto de la estrategia dominante, la cual ha ido simplificando los valores simbólicos del entorno intervenido. En su incansable explotación, también hoy en día, contemplamos como se ven afectadas en este proceso urbano, la zona periurbana y la zona rural. De igual modo, estas zonas estarían bajo la influencia del mercado global, con sus productos deslocalizados. Debido a lo cual, esta fuerza absorbe el estilo de vida regional, como diría Harvey (1977), y como mucho, preservaría aquellos elementos del pasado, que considera rentables para su uso turístico. La urbe abandona su tradicional aspecto y se va fragmentando con unos límites imprecisos. "Como consecuencia, ya no existe una frontera entre lo urbano y lo rural, en un territorio remendado donde se intercalan trozos de naturaleza" (Paz, 2011, p. 403). Ante esta valoración de la situación, nos hallamos en un período delicado y de urgente renovación de paradigma. Como ya detectaba a finales del siglo XX Harvey (1977) "Queda para la teoría revolucionaria explorar el camino que va de un urbanismo basado en la explotación a un urbanismo apropiado para la especie humana" (p.330).

Por otro lado, los instrumentos tecnológicos de nuestra era digital, como los GPS, nos facilitan cualquier dato de localización al instante. Pero, sin cuestionar la funcionalidad de uso de este tipo de información, podemos manifestar que también estos artilugios han contribuido a la consolidación de una única mirada sobre el paisaje, tendente hacia una visualización homogénea y reduccionista. Por este motivo, señalamos primordial el cambio también, en el uso de estas herramientas. Ya que podrían contribuir a mostrar toda esa variedad acumulada, tan necesaria para la identidad de un lugar. Así pues, la cartografía digital de este siglo podría reunir todos aquellos fragmentos de significado, sin discriminación alguna, y así poder participar en la construcción de una mirada múltiple. Una cartografía que represente con un lenguaje simbólico el paisaje de nuestro tiempo. Para ello, es esencial "reconocer el paso del tiempo" (Recasens, 2014, p.103). Precisamos de los trazos y relatos del pasado, para configurar mapas que permitan la exploración en el tiempo, como alternativa de diálogo. De este modo, podríamos considerar la aplicación presentada, como un ejemplo que busca combatir esa mirada única sobre nuestro territorio. De manera específica, esta herramienta apuesta por el acceso y el conocimiento de elementos singulares del pasado, que hoy en día, resultarían invisibles para la cartografía convencional. Al mismo tiempo, valoramos adecuado su exhibición en un ámbito educativo, ya que puede favorecer, en las jóvenes generaciones, en el conocimiento y respeto por los paisajes culturales. Y así, establecer puentes de convivencia con las experiencias contemporáneas. "Tener en cuenta los ecosistemas naturales y los paisajes transformados históricamente por el ser humano es uno de los principios del nuevo paisajismo de principios del siglo XXI" (Maderuelo, 2007, p.203). Principios, que nos encaminen hacia una sensibilidad contemplativa, más amplia y perdurable. 


\section{FUENTES REFERENCIALES}

Alessandri, C., Fani, A. (2008). De la "geografía de la acumulación" a la "geografía de la reproducción": un diálogo con Harvey. Scripta Nova: Revista Electrónica de Geografía y Ciencias Sociales, 12(270).

Bauman, Z. (2015). La globalización. Consecuencias humanas. Méjico: Fondo de Cultura Económica.

Conde, J. (2015). Atlas de paisajes de la memoria. Galicia 1579-1865. (tesis doctoral). Universidad da Coruña, España.

Corbera, M. (2016). El paisaje, su patrimonialización y el beneficio económico. Investigaciones Geográficas, 65, 9-24.

Harvey, D. (2013). Ciudades rebeldes. Del derecho de la ciudad a la revolución urbana. Madrid, España: Ediciones Akal.

Harvey, D. (2013). Urbanismo y desigualdad social. Madrid, España: Siglo XXI.

Lefebvre, H. (2013). La producción del espacio. Madrid, España: Capitán Swing Libros.

Lefebvre, H. (1972). La revolución urbana. Madrid, España: Alianza Editorial.

Lladó Mas, B. (2012). El “revés” del mapa: Notes al voltant de Brian Harley i Franco Farinelli. Documents D’anàlisi Geogràfica, 58(1), 165-176.

Llopis, A., Perdigón, L. (2016). Cartografía histórica de la ciudad de Valencia (1608-1944). Valencia: Universitat Politècnica de València. Maderuelo, J. (2007). Paisaje y arte. Madrid, España: Abada Editores.

Maderuelo, J. (2010). El paisaje urbano. Estudios Geográficos, 71(269), 575-600.

Parellada, C. A. (2017). Los mapas históricos como instrumentos para la enseñanza de la historia. Tempo e Argumento, 9(21), $312-337$. Paz, B. (2011). Una mirada artística del paisaje urbano. Espacio, Tiempo y Forma, Serie VII, O(24), 395-415.

Recasens, A. (2014). Espacios, experiencias y recorridos interiores. URBS: Revista De Estudios Urbanos y Ciencias Sociales, 4(1), 95-110. 